\title{
The Effect of Relative Wages and External Shocks on Public Sector Turnover*
}

\author{
STEVE BRADLEY and \\ COLIN GREEN \\ Department of Economics, The Management \\ School, Lancaster University
}

\author{
JOHN MANGAN \\ Economics and Law Research Unit, \\ University of Queensland
}

\begin{abstract}
We use a unique database to investigate the determinants of quits and terminations amongst public servants where relative wages, job status and external shocks are used as explanatory variables. It is shown that in comparison with others in the public sector, nurses and teachers on permanent contracts are more likely to quit. More generally, both relative wages and external shocks are found to be an important determinant of turnover behaviour. The public policy implications of these findings are discussed.
\end{abstract}

\section{Introduction}

The operation of the public sector labour market plays a major part in determining the efficiency and scope of government activity. Interest in this issue has been heightened by a renewed commitment by governments to the effective organisation and delivery of public services, particularly in the health and education sectors. ${ }^{1}$

\footnotetext{
* The data used in this article were kindly supplied by the Queensland Public Service, and we are grateful to Dave Stott for providing excellent research assistance and Geraint Johnes and Gareth Leeves for commenting on an earlier draft. Bradley also thanks the School of Economics, University of Queensland, for the provision of excellent facilities to allow the completion of this article.

JEL classifications: I10, J22, J44

Correspondence: John Mangan, Department of Economics, School of Economics, University of Queensland, Brisbane, Old., Australia. Email: j.mangan@ uq.edu.au

${ }^{1}$ For example, the UK Cabinet Office's 1999 White Paper on Modernising Government set out an ambitious agenda to 'reinvent' and improve many aspects of public service delivery.
}

Furthermore, the OECD (1999) has identified a number of challenges in making the public sector an effective 'employer of choice' in the contemporary labour market. Amongst the most important of these challenges are recruitment and retention problems, giving rise to critical skill shortages in occupations, such as nursing and teaching (Belfield \& Marsden, 2006).

Despite these policy demands, there is relatively little known about the operation of public sector labour markets. Of those studies that do exist, the majority analyse the public-private sector wage differential (Borland \& Gregory, 1999), or turnover amongst specific occupational groups, such as nurses and teachers (Imazeki, 2005). Relatively few studies investigate turnover rates for the whole sector. An exception is Borjas (2003), but his focus is on the effect of relative wage compression in the US public sector on the recruitment and retention of high-skill workers. Similar work has been conducted by Nickell and Quintini (2002) for the UK and Kim (1999) for the USA, who find that the relative pay of public sector workers has fallen, 
especially amongst civil servants, teachers and nurses, which partly explains the decline in the average quality of these groups of workers. Harris and Adams (2007) provide evidence that teacher turnover in the USA is not higher than that of comparable professions.

Specific studies of nurses and teachers offer conflicting results on the impact of relative wages on turnover. Dolton and van der Klaauw $(1995,1999)$ show that relative wages are an important explanation of teacher turnover. Chevalier et al. (2007) demonstrate that UK graduates have become progressively less likely to choose to enter the teaching profession because of their sensitivity to relative wages. Similarly, Mont and Rees (1996) show for the USA that higher salaries reduce turnover. Relative wages and conditions of work would therefore appear to be important determinants of teacher turnover.

However, Stinebrickner (2002) finds that teachers in the USA are not 'lured' away from teaching by better-paid jobs. Instead, the majority of exits from teaching are to 'inactivity', to raise newborn children. Similarly, Shields and Ward (2001) argue that relative pay has been overemphasised in discussions of turnover amongst nurses in the British public sector. They find that dissatisfaction with promotion and training opportunities have a stronger impact on intentions to quit than workload and pay. Ahlburg and Mahoney's (1996) study of US nurses and Frijters et al.'s (2004) study of UK teachers also found that relative pay had a limited impact on retention. Hence, the relationship between outside factors and nurse, teacher and more broadly public sector turnover remains an open question.

The article addresses a number of issues. First, what factors cause labour turnover amongst public servants, and in particular, what is the impact of relative wages, external shocks and job status, such as the distinction between permanent and temporary workers? Second, are there differences in turnover behaviour between teachers and nurses, on one hand, and the rest of the public service on the other hand? Third, are there variations in quitting and termination behaviour? Finally, it examines the public policy implications of its findings.

We use administrative records for approximately 200,000 public sector workers across a range of state government departments in Queensland, Australia, to examine these ques- tions. In addressing these questions, we disaggregate worker turnover into quits (i.e. a voluntary exit) and terminations (i.e. an involuntary exit). Using these data, we estimate semiparametric competing risks duration models of worker turnover, allow for time varying labour market shocks and control for unobserved heterogeneity.

A major contribution of our article is that we are able to paint a more complete picture of the labour turnover issues facing the public sector than has hitherto been possible. This results from considering the public sector labour force as a whole while retaining the ability to focus on the specific areas of nurses and teachers where much of the previous research has been concentrated. Insofar as the Queensland public sector is similar to the public sectors of other states and countries, then our results can be generalised.

\section{Data and Institutional Background}

The size, structure and operation of Australia's public sector labour market are most closely comparable to that of Canada, the UK and the USA. Employment in the extended public sector accounted for 18.7 per cent of total employment, slightly lower than the mean level of 20.5 per cent (see OECD, 1997). Compensation costs as a proportion of general government consumption expenditure in Australia are closest to the levels exhibited by the USA, UK, Canada and the Netherlands. The public-private sector wage differential of 1.25 for the period 19941997 for Australia is in the upper range of OECD estimates (OECD, 1997) and compares to an OECD average of 1.18. In view of these facts, we argue that the performance of Australia's public sector is comparable to that of other OECD countries.

Furthermore, the structure of Australia's public sector is similar to the US and Canadian systems, distributed across federal, state and local levels of government. State governments account for 65.8 per cent of all public sector employees and have responsibility for core services, such as education, health, emergency services and law enforcement. The remaining public sector employees work in the federal government (23 per cent) and local government (11.2 per cent). Time series data for Australia indicate that federal public sector employment as a proportion of total employment has been falling steadily since the 1980 s, largely as a 
result of the privatisation of public enterprises, from 30.9 per cent of the total employed workforce in mid-1983 to 19.7 per cent at the end of 2001 (Borland \& Gregory, 1999), which is also consistent with the experience of other OECD countries. Employment in the state and local levels of government remained constant, whereas employment in the private sector grew at approximately 3.8 per cent per annum.

The data used in this study are based on the administrative personnel records of the Queensland State Government. These data were collected to facilitate human resource management and are known as the Minimum Obligatory Human Resources Information (MOHRI) database. It represents the minimum level of human resource information that the Queensland Government's 25 agencies are required to collect and report to the central government agency for industrial relations purposes. The database holds information on approximately 200,000 public sector workers and in this study refers to the calendar year for $2001 .^{2}$ The main advantage of our dataset is that it covers the entire workforce, including 'new' and 'experienced' workers.

The composition and characteristics of the workforce, subdivided by contract type, are reported in Table 1. Females are in the majority, representing 63 per cent of the total workforce, and there are clear differences in the occupational distribution of employment for men and women. ${ }^{3}$ Female employment is concentrated in advanced/intermediate clerical, teaching and nursing, whereas males are more likely to be employed in managerial, other professional and associate professional jobs. ${ }^{4}$ Approximately 86 per cent of men and 83 per cent of women are employed in permanent

\footnotetext{
${ }^{2}$ Our analysis is actually based on 177,519 workers, which excludes casual workers because of their very short employment tenure.

${ }^{3}$ Occupation groups are derived from 1 digit ASCO codes, equivalent to the US DOT codes. The exception is for the professional group, which is disaggregated into Nurses, Teachers and Other Professionals (see ABS (1997) Australian Standard Classification of Occupations, 2nd edition, catalogue number 1220, AGPS, and Canberra for more details).

${ }^{4}$ Unfortunately, there is no education variable in the MOHRI, however, the occupation data are detailed and are likely to be highly correlated with the level of education of the worker.
}

jobs, with the remainder employed on fixedterm/temporary contracts. The occupational distribution of employment is similar for permanent and temporary workers for both males and females, except in nursing for females and associate professionals for males, where a significantly higher proportion is employed on permanent contracts. Note also the large proportions of males and females employed on temporary contracts in elementary clerical jobs.

Importantly, MOHRI includes information on whether a worker exits the public sector. This we use to measure turnover, hence all exits in this paper refer to workers leaving the public sector (not, for instance, moving between public sector departments). MOHRI also includes information on why the worker left, which includes quitting, termination (dismissal and non-renewal/termination of contract) and a range of other exits, such as retirement, death and ill-health. The former two we use as our measures of quitting and termination, respectively. ${ }^{5}$ A shortcoming of MOHRI is that we do not know anything about the destination of workers, hence we do not know if quitting workers left, for instance, for another (private sector) job or simply became unemployed or inactive.

The usefulness of the distinction between employee-initiated (quits) and employer-initiated (terminations) turnover has been a source of debate in the literature (McLaughlin, 1991). Whilst we do not add anything to this debate, in subsequent results, we do find distinctive patterns of quits and terminations for both permanent and temporary workers. Furthermore, statistical tests reject pooling of these two exit types, which implies that there is a behavioural distinction between quits and terminations, at least in our institutional setting.

Turnover is higher for temporary workers, which is perhaps unsurprising, although the extent of the difference between them and permanent workers is striking. The permanent public sector labour force experienced a 1-4 per cent overall turnover rate in 2001 , depending on whether exit from the sector was via a quit or a termination, versus $7-16$ per cent for the temporary workforce. The temporary workforce is also

\footnotetext{
${ }^{5}$ Note that in the subsequent duration analysis the other exit types are treated as censored events.
} 
TABLE 1

Workforce Characteristics by Contract Type, 2001

\begin{tabular}{|c|c|c|c|c|}
\hline & \multicolumn{2}{|c|}{ Permanent } & \multicolumn{2}{|c|}{ Temporary } \\
\hline & Males & Females & Males & Females \\
\hline \multicolumn{5}{|l|}{ Personal characteristics } \\
\hline $\operatorname{ATSI}^{\dagger}$ & 0.07 & 0.04 & 0.08 & 0.06 \\
\hline $\mathrm{NESB}^{\ddagger}$ & 0.08 & 0.07 & 0.06 & 0.05 \\
\hline Disabled & 0.08 & 0.06 & 0.05 & 0.05 \\
\hline Age (years) & 42.40 & 40.74 & 36.19 & 36.34 \\
\hline \multicolumn{5}{|l|}{ Wages and tenure } \\
\hline Wage rate $(\$ / \mathrm{h})$ & 26.68 & 25.60 & 22.63 & 22.27 \\
\hline Tenure (years) & 13.77 & 10.08 & 3.03 & 2.87 \\
\hline \multicolumn{5}{|l|}{ Occupational group } \\
\hline Managers & 0.10 & 0.04 & 0.02 & 0.02 \\
\hline \multicolumn{5}{|l|}{ Professionals } \\
\hline Nurses & 0.03 & 0.14 & 0.01 & 0.06 \\
\hline Teachers & 0.13 & 0.25 & 0.17 & 0.24 \\
\hline Other professionals & 0.20 & 0.12 & 0.29 & 0.18 \\
\hline Associate professionals & 0.24 & 0.11 & 0.13 & 0.09 \\
\hline Intermediate craft & 0.06 & 0.00 & 0.11 & 0.00 \\
\hline Advanced/intermediate clerical & 0.13 & 0.28 & 0.16 & 0.32 \\
\hline Intermediate production & 0.02 & 0.00 & 0.01 & 0.00 \\
\hline Elementary clerical & 0.01 & 0.01 & 0.06 & 0.07 \\
\hline Labourer & 0.07 & 0.05 & 0.05 & 0.02 \\
\hline \multicolumn{5}{|l|}{ Turnover rates } \\
\hline Quits & 0.03 & 0.04 & 0.09 & 0.07 \\
\hline Terminations & 0.01 & 0.01 & 0.16 & 0.16 \\
\hline Other ${ }^{\S}$ & 0.02 & 0.01 & 0.02 & 0.02 \\
\hline \multicolumn{5}{|l|}{ Working conditions } \\
\hline Agency size & 28,855 & 48,153 & 30,723 & 40,733 \\
\hline Establishment size $\mathrm{e}^{\dagger \dagger}$ & 1009 & 1147 & 917 & 863 \\
\hline Entry rates ${ }^{\neq \neq}$ & 0.04 & 0.05 & 0.38 & 0.36 \\
\hline Managers & \multicolumn{2}{|c|}{0.021} & \multicolumn{2}{|c|}{0.032} \\
\hline \multicolumn{5}{|l|}{ Professionals } \\
\hline Nurses & \multicolumn{2}{|c|}{0.081} & \multicolumn{2}{|c|}{0.092} \\
\hline Teachers & \multicolumn{2}{|c|}{0.039} & \multicolumn{2}{|c|}{0.037} \\
\hline Other professionals & \multicolumn{2}{|c|}{0.079} & \multicolumn{2}{|c|}{0.098} \\
\hline Associate professionals & \multicolumn{2}{|c|}{0.029} & \multicolumn{2}{|c|}{0.066} \\
\hline Intermediate craft & \multicolumn{2}{|c|}{0.061} & \multicolumn{2}{|c|}{0.042} \\
\hline Advanced/intermediate clerical & \multicolumn{2}{|c|}{0.038} & \multicolumn{2}{|c|}{0.097} \\
\hline Intermediate production & \multicolumn{2}{|c|}{0.039} & \multicolumn{2}{|c|}{0.024} \\
\hline Elementary clerical & \multicolumn{2}{|c|}{0.120} & & \\
\hline Labourer & & & & \\
\hline Observations & 56,697 & 93,207 & 9006 & 18,609 \\
\hline
\end{tabular}

Notes: 'Includes those who self-identify as originating from an Aboriginal or Torres Strait Islanders (ATSI) background. ${ }^{\ddagger}$ Includes those who self-identify as originating from a Non-English Speaking Background (NESB). ${ }^{8}$ Includes turnover due to: ill-health retirement, age retirement, voluntary early retirement, death, and pension (paid by agency). "Calculated as average number of employees per agency. ${ }^{\dagger}$ Calculated as average number of workers per postcode area by agency. ${ }^{\ddagger \pm}$ Due to small cell sizes for some occupations, we do not disaggregate occupational entry rates by contract status and gender.

characterised by a high entry rate - approximately 37 per cent were new appointees in 2001.
One possible conclusion from these findings is that temporary contracts are used as a screening device, to enable the employer to determine the 
TABle 2

Quits and Terminations by Workforce Characteristics, 2001

\begin{tabular}{|c|c|c|c|c|c|c|}
\hline & \multicolumn{2}{|c|}{ Quits } & \multicolumn{2}{|c|}{ Terminations } & \multicolumn{2}{|c|}{ Other } \\
\hline & Male & Female & Male & Female & Male & Female \\
\hline \multicolumn{7}{|l|}{ Personal characteristics } \\
\hline ATSI & 0.13 & 0.09 & 0.05 & 0.04 & 0.06 & 0.04 \\
\hline NESB & 0.06 & 0.05 & 0.04 & 0.04 & 0.06 & 0.05 \\
\hline Disabled & 0.12 & 0.15 & 0.07 & 0.07 & 0.13 & 0.12 \\
\hline Age (years) & 38.70 & 36.24 & 39.09 & 36.70 & 47.25 & 47.34 \\
\hline \multicolumn{7}{|l|}{ Wages and tenure } \\
\hline Wage rate $(\$ / \mathrm{h})$ & 23.53 & 21.07 & 24.70 & 23.44 & 25.72 & 22.78 \\
\hline Tenure (years) & 6.93 & 5.38 & 5.77 & 3.33 & 15.52 & 11.97 \\
\hline \multicolumn{7}{|l|}{ Occupational group } \\
\hline Managers & 0.07 & 0.05 & 0.06 & 0.02 & 0.11 & 0.03 \\
\hline \multicolumn{7}{|l|}{ Professionals } \\
\hline Nurses & 0.04 & 0.14 & 0.00 & 0.01 & 0.00 & 0.05 \\
\hline Teachers & 0.06 & 0.09 & 0.23 & 0.30 & 0.11 & 0.19 \\
\hline Other professionals & 0.28 & 0.20 & 0.22 & 0.14 & 0.18 & 0.11 \\
\hline Associate professionals & 0.17 & 0.11 & 0.13 & 0.10 & 0.22 & 0.10 \\
\hline Intermediate craft & 0.13 & 0.01 & 0.05 & 0.00 & 0.03 & 0.00 \\
\hline Advanced/intermediate clerical & 0.13 & 0.32 & 0.15 & 0.32 & 0.15 & 0.32 \\
\hline Intermediate production & 0.02 & 0.00 & 0.03 & 0.00 & 0.05 & 0.01 \\
\hline Elementary clerical & 0.03 & 0.04 & 0.07 & 0.08 & 0.02 & 0.06 \\
\hline Labourer & 0.07 & 0.05 & 0.07 & 0.02 & 0.12 & 0.13 \\
\hline \multicolumn{7}{|l|}{ Working conditions } \\
\hline Agency size & 23,581 & 34,299 & 26,488 & 34,851 & 22,609 & 36,821 \\
\hline Establishment size & 783 & 919 & 592 & 589 & 647 & 593 \\
\hline Establishment sick rate & 1.78 & 1.90 & 1.75 & 1.77 & 1.97 & 2.01 \\
\hline Observations & 3024 & 5291 & 2305 & 4096 & 1018 & 1147 \\
\hline
\end{tabular}

Notes: ATSI, Aboriginal or Torres Strait Islanders background; NESB, Non-English Speaking Background).

quality of the match, and as a means of adjusting the size of the workforce. ${ }^{6}$ This is further corroborated when we disaggregate turnover by quits and terminations. ${ }^{7}$ Temporary workers dominate both groups, accounting for approximately 26-32 per cent of all quits and a massive 72-99 per cent of terminations. Table 2 shows that it is workers at the upper end of the occupational hierarchy who have higher than average rates of quitting. For example, female nurses account for 13 per cent of the workforce (see Table 1) with a high quit rate (14 per cent) and a low termination rate (1 per cent). In contrast, the share of female teachers in the sector is 25 per cent, with a lower

\footnotetext{
${ }^{6}$ An alternative supply-side explanation is that workers are looking for temporary contracts as part of a lifestyle choice or in conjunction with other activities such as study.

${ }^{7}$ Where terminations cover dismissal and nonrenewal of contract.
}

proportion of quitters ( 9 per cent) and a much higher proportion of terminations (30 per cent). These outcomes are partly explained by the different shares of temporary workers recruited to these occupations. However, turnover rates are also high for other professionals, associate professionals, such as technicians, and advanced/ intermediate clerical workers (Mangan, 2000).

\section{A Theoretical and Econometric Framework}

A variety of theoretical models have been developed to explain worker mobility, including human capital and search/matching models (Flinn, 1986; Meitzen, 1986; Farber, 1994; Jovanovic \& Moffitt, 1990), which we use here as a framework for understanding the mobility decisions of public sector workers and to motivate the econometric approach.

Matching models rely on the presence of imperfect information and on the idea that job matches are experience goods (see Jovanovic, 
1979). It is assumed that both jobs and workers have heterogeneous productivities, and the problem for the employer is to optimally assign workers to jobs. It is also assumed that employers can contract with workers on an individual basis. Employers offer higher rewards for workers who are regarded as 'better' matches, which in the context of the public sector may occur through promotion within the internal labour market. Because of the difficulty of firing workers once they are on permanent contracts, especially in the public sector, employers may use probationary periods, and more recently temporary contracts, so that relatively unproductive workers can be released (Bishop, 1990; Green \& Leeves, 2004). However, the quantity and quality of information about the worker and the employer is likely to increase over time, which gives rise to either optimal matches, perhaps through job reassignment, or turnover.

Worker turnover in the public sector can be viewed as a function of the expected quality of the match between a worker-job pairing, $\mu$, which varies by each pairing and through time, $t$; information about a worker's previous performance or output, $q$; and the precision of the match, $p(t)$. Workers quit if the expected discounted benefits of alternative offers, in terms of the wage or contract status, for instance, exceed the expected discounted direct and indirect costs of job changing. An employer terminates employment if at time $t$ they found that $\mu_{t}<r_{t}^{e}$, the employer's reservation utility or productivity level. It could also be expected that a higher rate of quitting than termination is observed if workers learn more quickly than employers about the quality of the match. Nevertheless, quit and termination probabilities decrease with job tenure because 'mismatches' are detected early. However, because of the need to learn about the quality of the match, the associated hazards are likely to be non-monotonic. Specifically, it is expected that the baseline hazard will initially increase and then flatten once information about the quality of the match has been observed by the worker and the firm. ${ }^{8}$ In

\footnotetext{
${ }^{8}$ It is worth noting that workers in the Queensland public service can be employed on contracts of 3,6 or 12 months, which are renewable over an indefinite period, and permanent workers have a probationary period of 13 months. One may therefore expect to observe spikes in the hazard as employers (and workers) are required to renew the contract in the light of information revealed about the quality of the match.
}

the case of temporary contracts in the public sector, where there is greater uncertainty regarding a worker's productivity, and hence the quality of the match, we would expect their baseline hazard to be higher than that for permanent workers.

From this we can formulate the following hazard models:

$$
\begin{aligned}
h^{Q} & =f\left(\mu_{t}, q, p(t)\right), \\
h^{T} & =f\left(\mu_{t}, q, p(t)\right) .
\end{aligned}
$$

Information about $q$ is a function of worker tenure, which we observe in our data and is reflected in the shape of the baseline hazard. We cannot observe $\mu_{t}$, thus we proxy this by worker characteristics (e.g. ethnic background, disability), the working conditions (e.g. establishment size and establishment sickness record) and the occupation to which workers are assigned. It is difficult to observe the precision of the match, $p(t)$. However, due to the difficulty in dismissing permanent workers, temporary contracts are more likely to be used where there is less certainty about the quality of the match.

So far we have assumed that worker turnover is a function of a matching process internal to the public sector, when in practice there may also be external shocks arising in the labour market or from government policy, which also result in worker turnover. Public sector workers are clearly exposed to public expenditure cuts, for instance, but may also be exposed to events in the external labour market, insofar as a high local unemployment rate, for instance, will encourage immobility because the external job offer arrival rate falls. Higher relative wages may also act as a pull factor, as suggested by some of the previous literature. Equations (1a) and (2a), therefore, need to be modified to include the unemployment rate $\left(u_{t}\right)$, our proxy for shocks, and the relative wage $\left(w_{r}\right)$ :

$$
\begin{aligned}
& h^{Q}=f\left(\mu_{t}, q, p(t), u_{t}, w_{r}\right), \\
& h^{T}=f\left(\mu_{t}, q, p(t), u_{t}, w_{r}\right) .
\end{aligned}
$$

Our observed covariates are collected in a vector, $\boldsymbol{x}$, however, it is possible that unobservable differences between workers, such as motivation and attitudes to work, also affect their mobility decision. This is allowed for in the econometric modelling. 
Following Bradley et al. (2003), we view the behaviour of workers in the public sector as a semi-Markov process with individuals entering the sector either via a temporary contract $(j=1)$ or a permanent contract $(j=2)$ and exiting either by quitting $(k=1)$ or separating $(k=2)$. Thus, we have two origin states and two reasons for exit, or destination states, and all spells in the public sector are assumed independent of each other for simplicity. For spell $i$, tenure is grouped into $D_{i}$ intervals $\left(d_{l-1}, d_{1}\right], l=1, \ldots, D_{i}$ with $d_{0}=0 .{ }^{9}$

Following Prentice and Gloeckler (1978), we adopt a random effect discrete time representation of the continuous time competing risk model so that the likelihood for spell $i$ of type $j k$ is given by

$$
\begin{aligned}
L_{i j k}=\int & \prod_{l=1}^{D_{i}} h_{i j k l}\left(v_{i j k}\right)^{y_{i j k l}}\left(1-h_{i j k l}\left(v_{i j k}\right)\right)^{\left(1-\Sigma_{k} y_{i j k l}\right)} \\
& \times D G\left(v_{j k} ; \sigma_{j k}\right),
\end{aligned}
$$

where $y_{i j k l}=1$ for a $j$ to $k$ transition in interval $l$, and 0 otherwise. The probability of a $j k$ transition in interval $l$ (the discrete time hazard) is given by

$$
\begin{aligned}
\operatorname{Pr}\left(y_{i j k l}=1 \mid v_{i j k}\right) & =h_{i j k l}\left(v_{i j k}\right) \\
& =1-\exp \left[-\exp \left(\eta_{i j k}(l)+v_{i j k}\right)\right],
\end{aligned}
$$

where $\eta_{i j k}(l)=\log \left\{\Lambda_{i j k}\left(d_{l}\right)-\Lambda_{i j k}\left(d_{l}-1\right)\right\}, \Lambda_{i j k}\left(d_{l}\right)=$ $\int_{0}^{d_{l}} \theta_{i j k}(t) \mathrm{d} t$, and $\theta_{i j k}(t)$ is the continuous time hazard for leaving origin state $j$ for destination $k$ at duration $t . G\left(v_{j k} ; \sigma_{j k}\right)$ is the distribution function for the unobserved heterogeneity, or random effects $\left(v_{i j k}\right)$, and has dispersion parameter $\sigma_{j k}$. In this article, we model the unobserved heterogeneity using normal mixing with mean zero and variance $\sigma_{j k}{ }^{10}$

\footnotetext{
${ }^{9}$ In our data, we observe the date started in the public sector and the date they exit. This is divided into two monthly intervals, except for workers with very long tenures where it is grouped in year bands.

${ }^{10}$ Several alternatives to using Gaussian mixing exist, such as the gamma distribution and the nonparametric mass point approach suggested by Heckman and Singer (1984). The non-parametric approach is the least the restrictive, however, when we adopted this approach our models did not converge.
}

Under the proportional hazard assumption

$$
\eta_{i j k}(l)=\beta_{0 j k}+\beta_{1 j k} x_{i j k l}+\psi_{j k l},
$$

where $x_{i j k l}$ is a vector of covariates, some of which vary over time $(l), \beta_{1 j k}$ is a vector of regression parameters and the $\psi_{j k l}$ are constants, such that

$$
\psi_{j k l}=\log \left\{\Lambda_{0 j k}\left(d_{l}\right)-\Lambda_{0 j k}\left(d_{l}\right)\right\},
$$

$\Lambda_{0 j k}\left(d_{l}\right)$ is the integrated baseline hazard. The start and end points used to determine $\psi_{j k l}$ often take different values to those of the time intervals $\left(d_{l-1}, d_{l}\right]$. When this happens we can write $\psi_{j k l}=\gamma_{j k l} I(l) ; I(l)$ is an indicator of the form $I(r<l \leq m)$, where $r$ and $m$ are the start and end points of an interval for duration.

This equation is estimated separately for each origin-destination pair, $j k$, which means that we assume that the hazards for each competing risk are mutually independent. This implies that the spell specific random effects $\left(v_{i j k}\right)$ are uncorrelated across the origin-destination pairs.

The difficulty in interpreting the coefficients from a competing risks model is well documented (Lancaster, 1990; Thomas, 1996), therefore to aid interpretation, we compute marginal effects following the approach suggested by Thomas (1996), which is discussed in some length in Andrews et al. (2002). Thus, in our empirical analysis, we report the estimated marginal effects and the probability value associated with the estimated coefficient obtained from the competing risk model. Marginal effects must sum to zero. Note that, although the hazard of exit varies over person-time, implying variation in the marginal effects, we estimate mean expected waiting times and then compute the marginal effects of the covariates at this point, that is, at $j=16$ for males and $j=18$ for females. As these marginal effects sum to zero, and we have two exit states, for brevity only the marginal effects for quits are reported.

\section{Results}

As a point of comparison, Figure 1 presents the estimated baseline hazard for overall turnover. In Figures 2 and 3, we report the estimated baseline hazards disaggregated by type of turnover. In the case of quits (see Fig. 2a-c), there is very little difference between the shape of the baseline hazard for permanent workers (Fig. 2b) and all quits (Fig. 2a), most likely because there are relatively few permanent 
FIGURE 1

Baseline Hazards for Combined Destinations. (a) Permanent and Temporary Contracts Combined. (b) Permanent Contracts. (c) Temporary Contracts.

(a) Permanent and temporary contracts combined

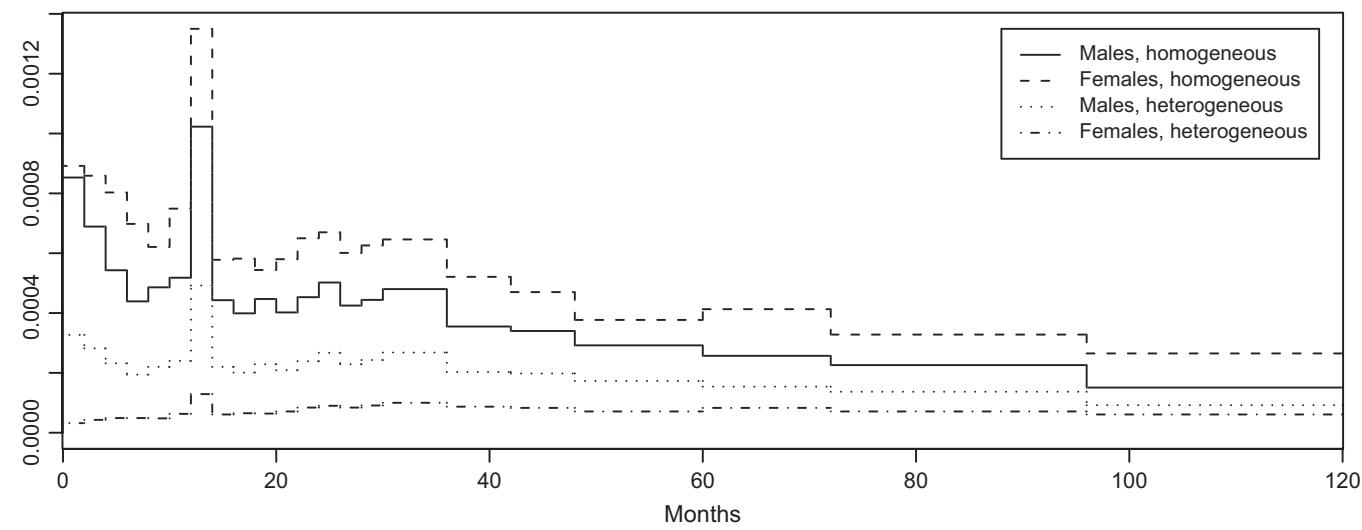

(b) Permanent contracts

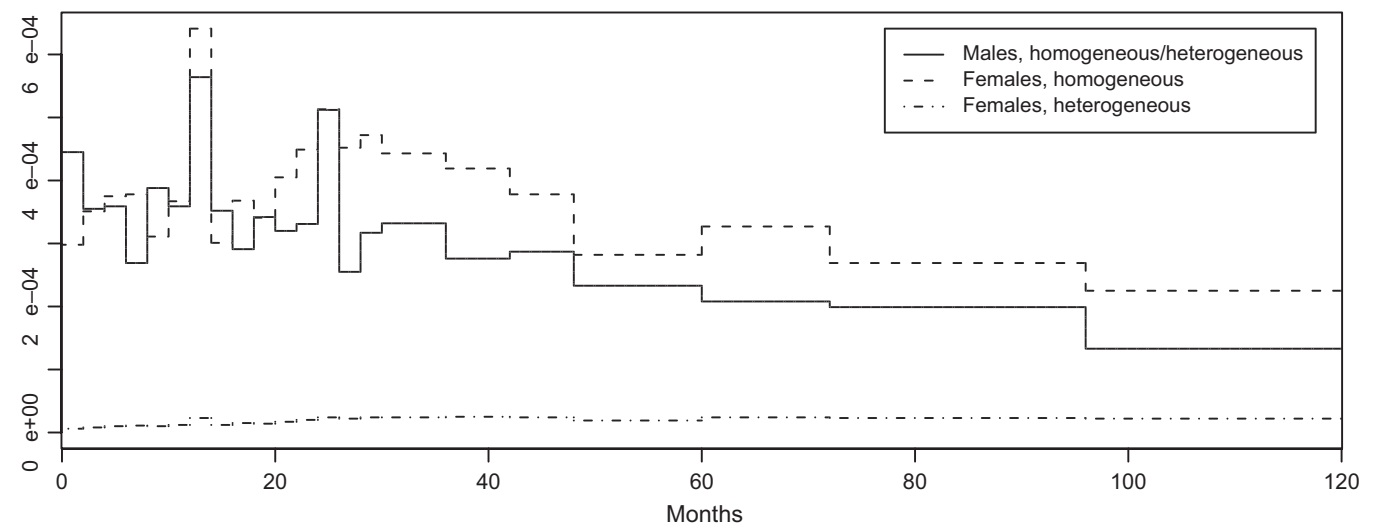

(c) Temporary contracts

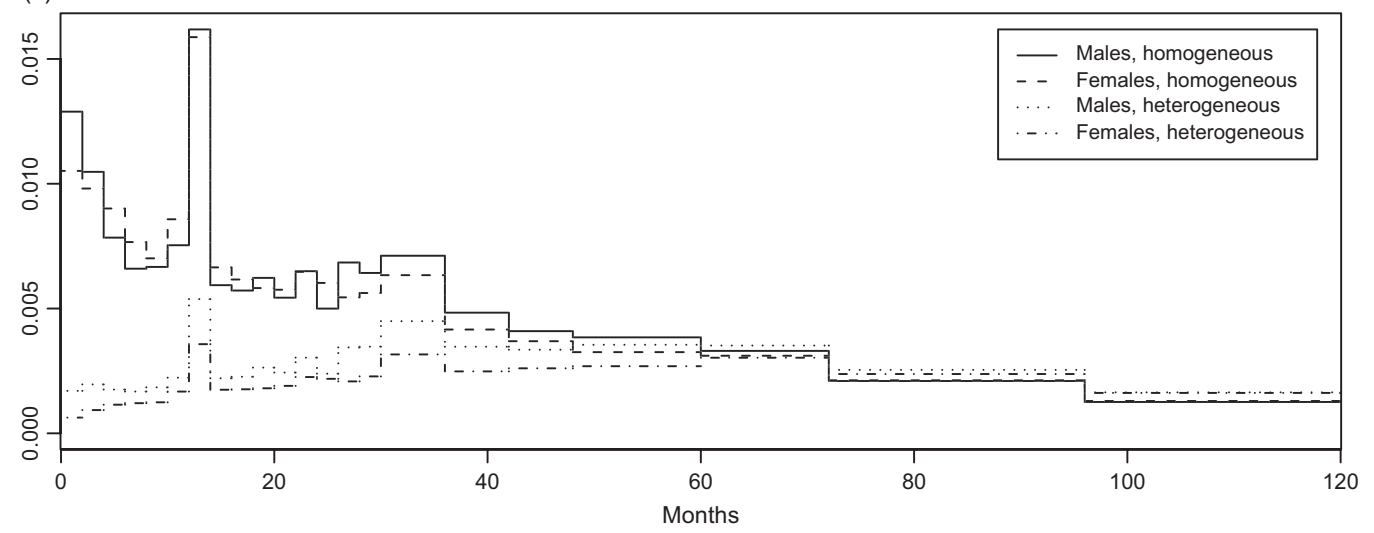

(C) 2012 The Economic Society of Australia 
FIGURE 2

Baseline Hazards for Quits. (a) Permanent and Temporary Contracts Combined. (b) Permanent Contracts.

(c) Temporary Contracts.

(a) Permanent and temporary contracts combined

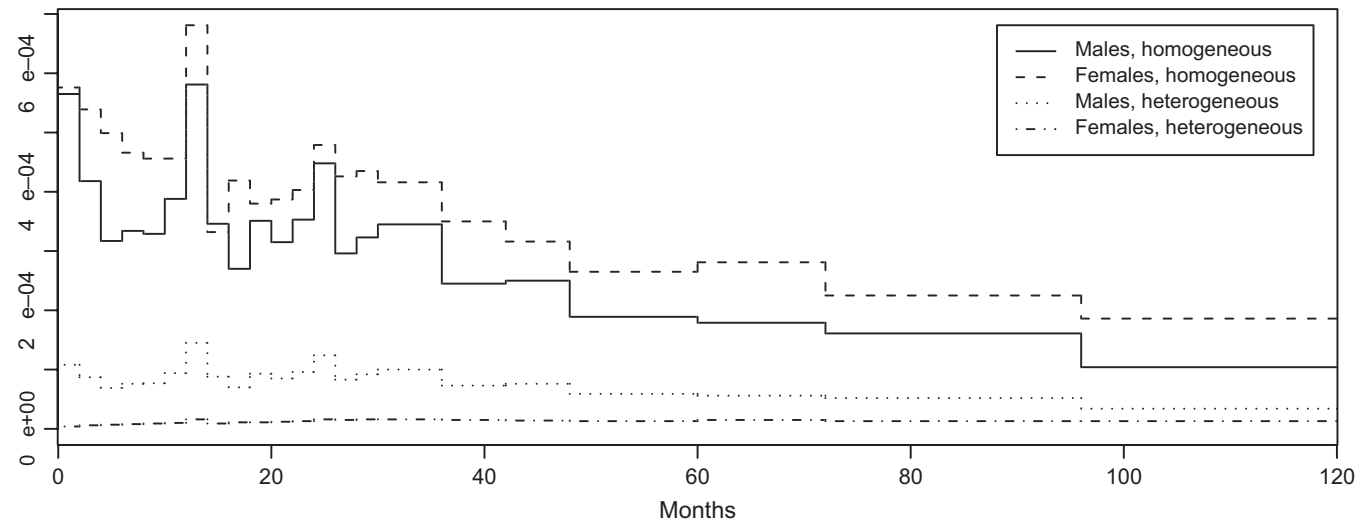

(b) Permanent contracts
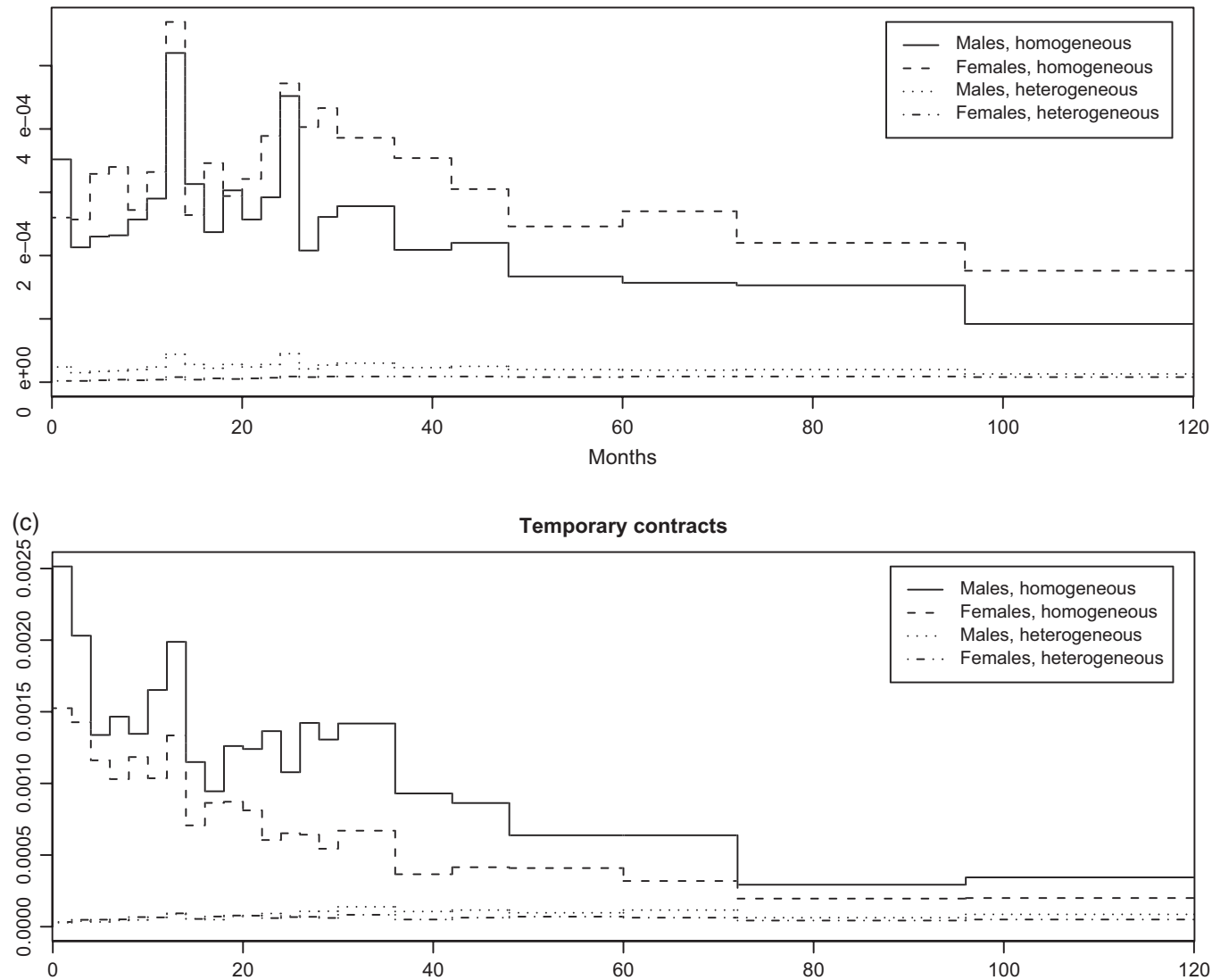

(c) 2012 The Economic Society of Australia 
FiguRE 3

Baseline Hazards for Separations. (a) Permanent and Temporary Contracts Combined. (b) Permanent Contracts. (c) Temporary Contracts.

(a)

Permanent and temporary contracts combined

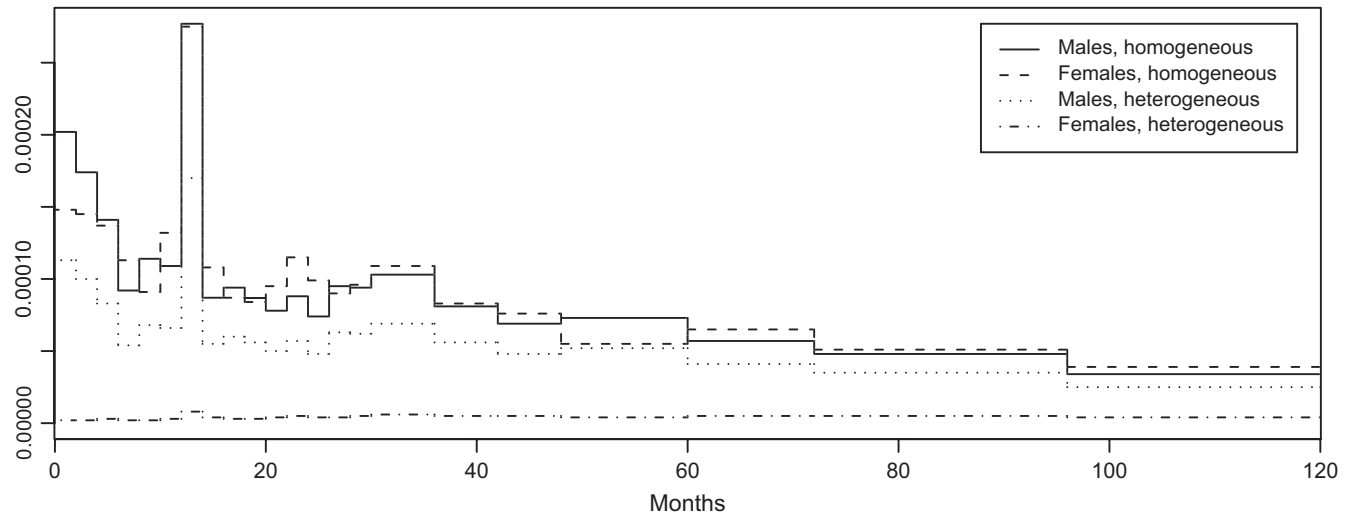

(b)

Permanent contracts

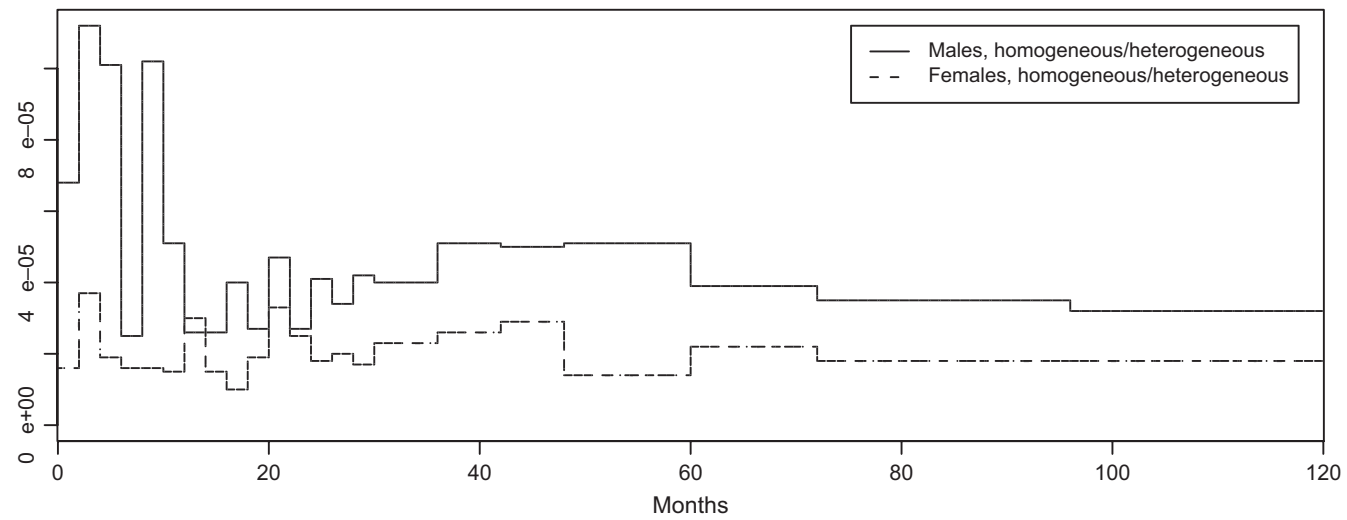

(c)

Temporary contracts

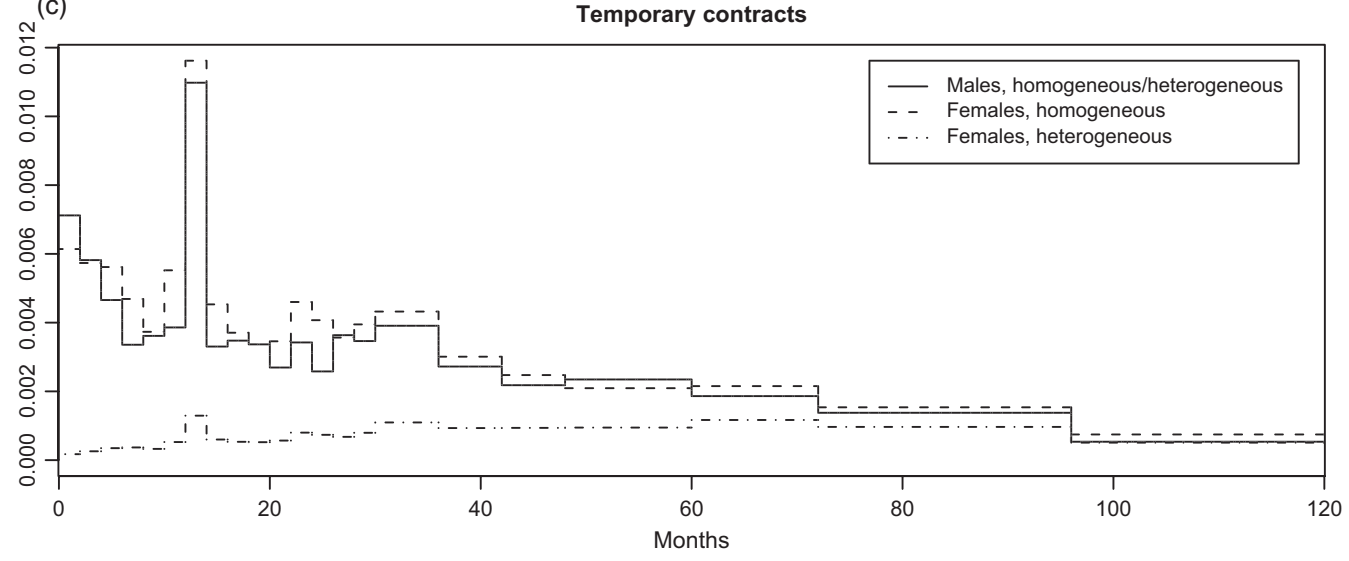

(C) 2012 The Economic Society of Australia 
workers who quit. Furthermore, once allowance is made for unobserved heterogeneity amongst workers, the quitting hazard for permanent workers is flat. The main difference occurs between temporary workers who quit (Fig. 2c) and all quits (Fig. 2a). However, once again controlling for unobserved heterogeneity results in the hazard of exit for temporary workers who quit becoming flat.

A different picture emerges for workers whose contracts are terminated (see Fig. 3a-c). Combining workers on permanent and temporary contracts (Fig. 3a), we observe that for males and females the hazards of exit from the homogenous models are initially high, fall and then exhibit a spike at 12 months. This picture is essentially replicated for males once unobserved heterogeneity is taken into account, although the hazard does shift downwards, whereas the equivalent hazard for females is flat. Disaggregating by contract status we see that it is temporary workers who drive the pattern of behaviour observed in Figure 3(a).

Our theoretical framework suggests that the hazard to quitting will be higher than the hazard to separation. Furthermore, the baseline hazards for workers on temporary contracts should be higher than those for workers on permanent contracts if temporary workers are more imprecisely matched. Since it is difficult to compare the baseline hazards on Figures 2 and 3, due to the fact that they have different scales, Figure 4 reports transition intensities by gender. ${ }^{11}$ For males and females, workers on temporary contracts are more likely to exit the public sector, overwhelmingly through termination. In the case of males on temporary contracts who exit involuntarily, there is some evidence that employers take time to learn about the quality of the match. This is reflected by the non-monotonic but rising transition intensity up to 20 months. It is difficult to see any difference between the other transition intensities; therefore Figure 5 omits the schedule for temporary worker terminations. Of the three remaining groups, males exiting from the public sector are more likely to occur amongst workers on temporary contracts who

\footnotetext{
${ }^{11}$ Transition intensities are computed by re-scaling the hazards so that they sum to 1 in each time interval. Since all of our models are estimated with the same number of time periods, are specified identically, and are estimated independently, we are able to combine models in this way.
}

quit, followed by those on permanent contracts who separate. For females, the reverse holds in the first few months, but from 12 months temporary quits are greater than permanent terminations. In the case of both males and females, permanent workers are less likely to quit.

In summary, we find evidence of non-monotonic hazards for males on permanent contracts and for temporary workers, even after allowance is made for unobserved heterogeneity. We also find evidence of spikes at 12 and 24 months, followed by a flat hazard, which corresponds more closely with an institutional rules-based approach to employee screening rather than a matching approach. Moreover, although temporary workers are more likely to exit the sector than permanent workers, as our theoretical framework suggests, terminations dominate quits, which implies that this group of workers is used as a buffer to external shocks.

\section{(i) The Effect of Relative Wages and External Shocks}

If the size of the public sector workforce does now respond to the business cycle, then terminations should be pro-cyclical. Alternatively, if governments use the public sector as a vehicle for achieving their objectives with respect to affirmative action then terminations may be counter-cyclical. With respect to quits, as better (and more highly paid) external job opportunities become scarce we would expect quits to fall and hence be counter-cyclical.

We test these hypotheses by incorporating into our models the time varying local unemployment rate. ${ }^{12}$ Tables 3 and 4 show that, except for females on temporary contracts, a higher local unemployment rate is associated with an increase in terminations, which is a counter-cyclical effect, and a decrease in quitting, a pro-cyclical effect. The finding that quits are pro-cyclical is in line with existing evidence (see Contini \& Ravelli, 1997 for an overview), whereas the countercyclical termination effect is new.

To capture the attractiveness of alternative job matches outside of the public sector, and following the existing literature with respect to teachers and nurses, we include a non-time

\footnotetext{
${ }^{12}$ Specifically, we map to each worker's tenure in the sector the quarterly unemployment rate at the Statistical Local Area level, which encompasses several local government areas.
} 
Figure 4

Transition Intensities by Contract Type and Type of Turnover. (a) Females. (b) Males.

(a)

Females

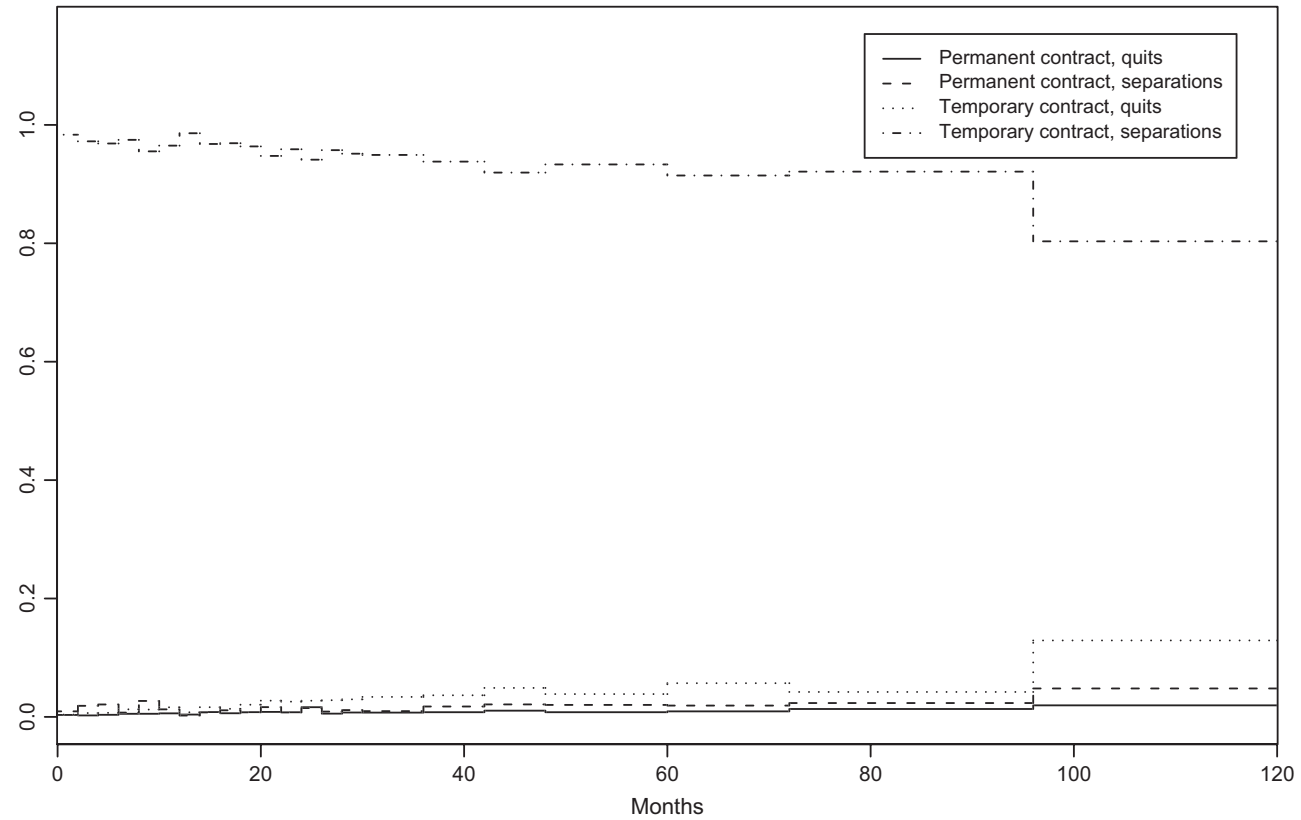

(b)

Males

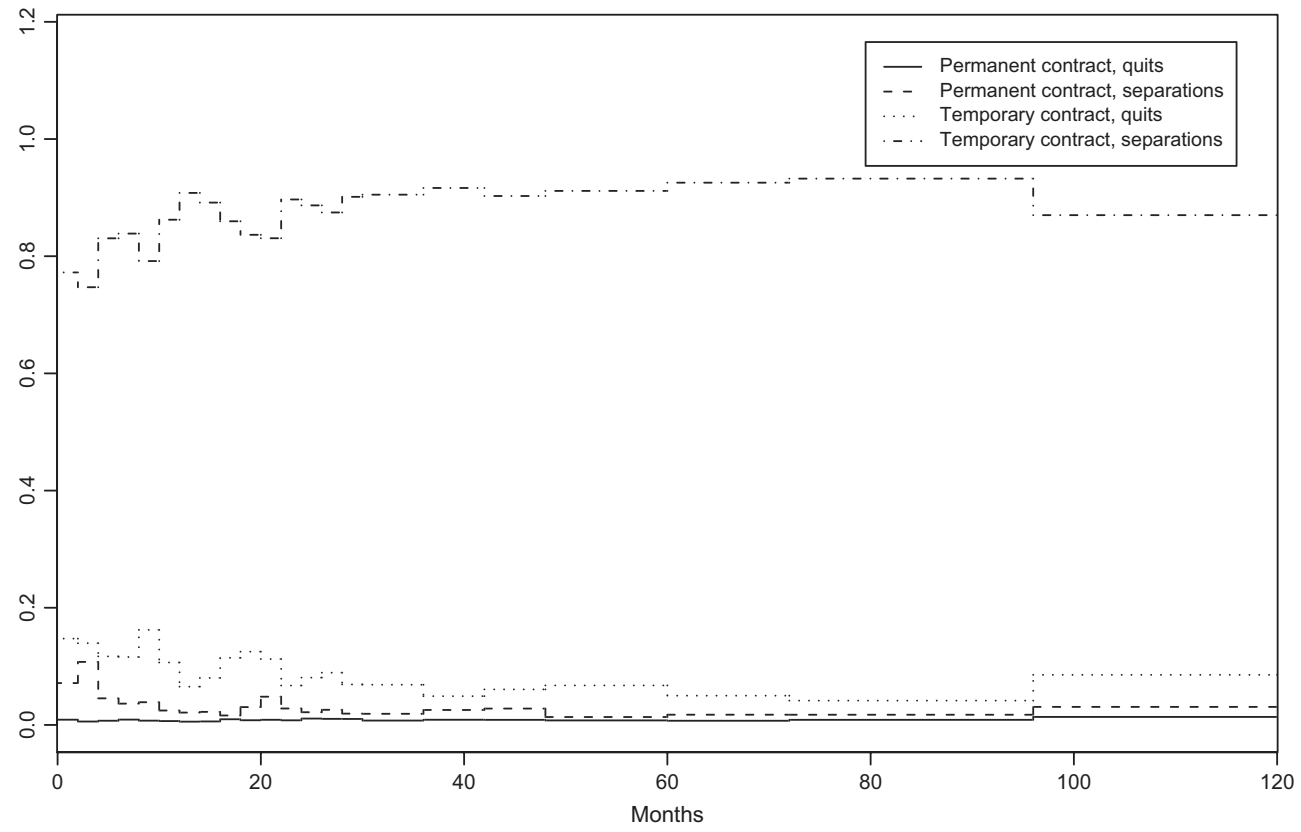

(C) 2012 The Economic Society of Australia 
FIGURE 5

Transition Intensities by Contract Type and Type of Turnover. (a) Females. (b) Males.

(a)

Females

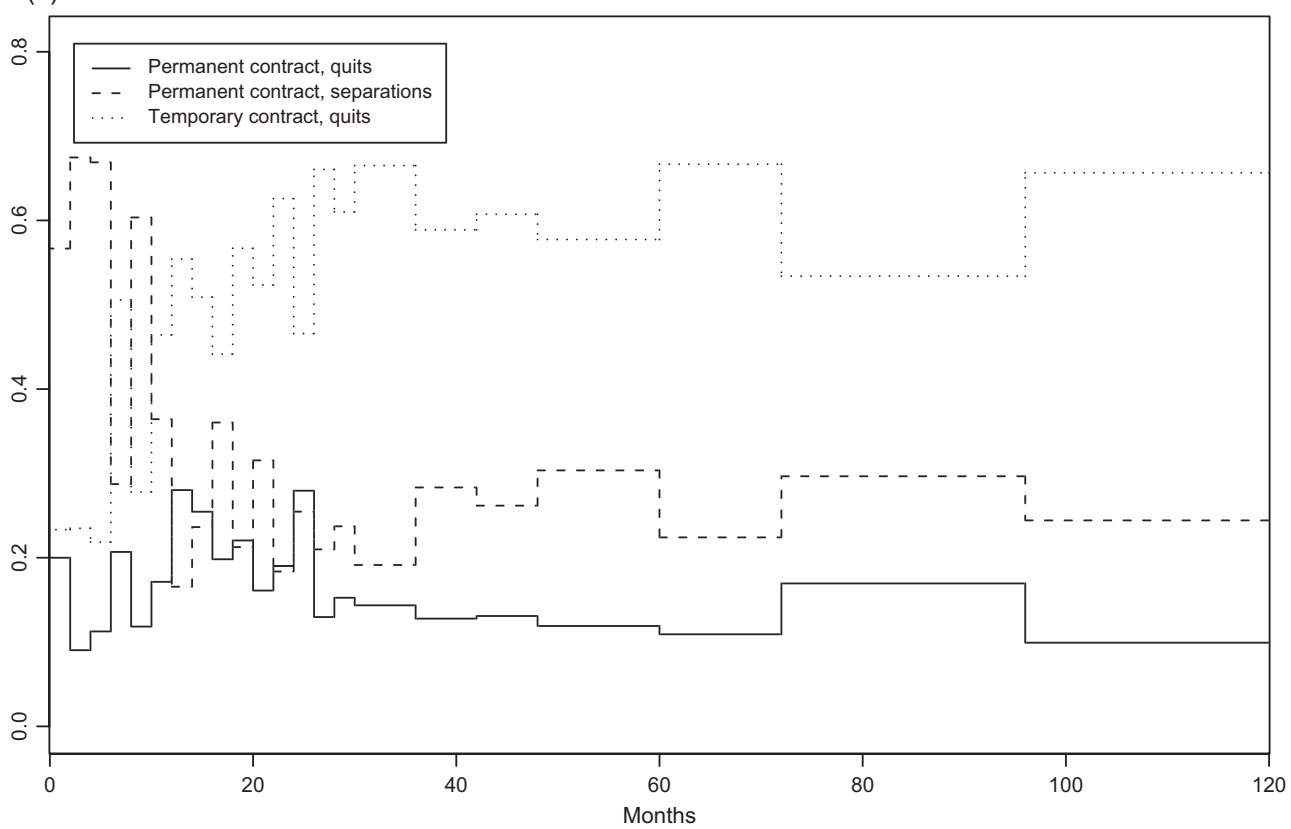

(b) Males

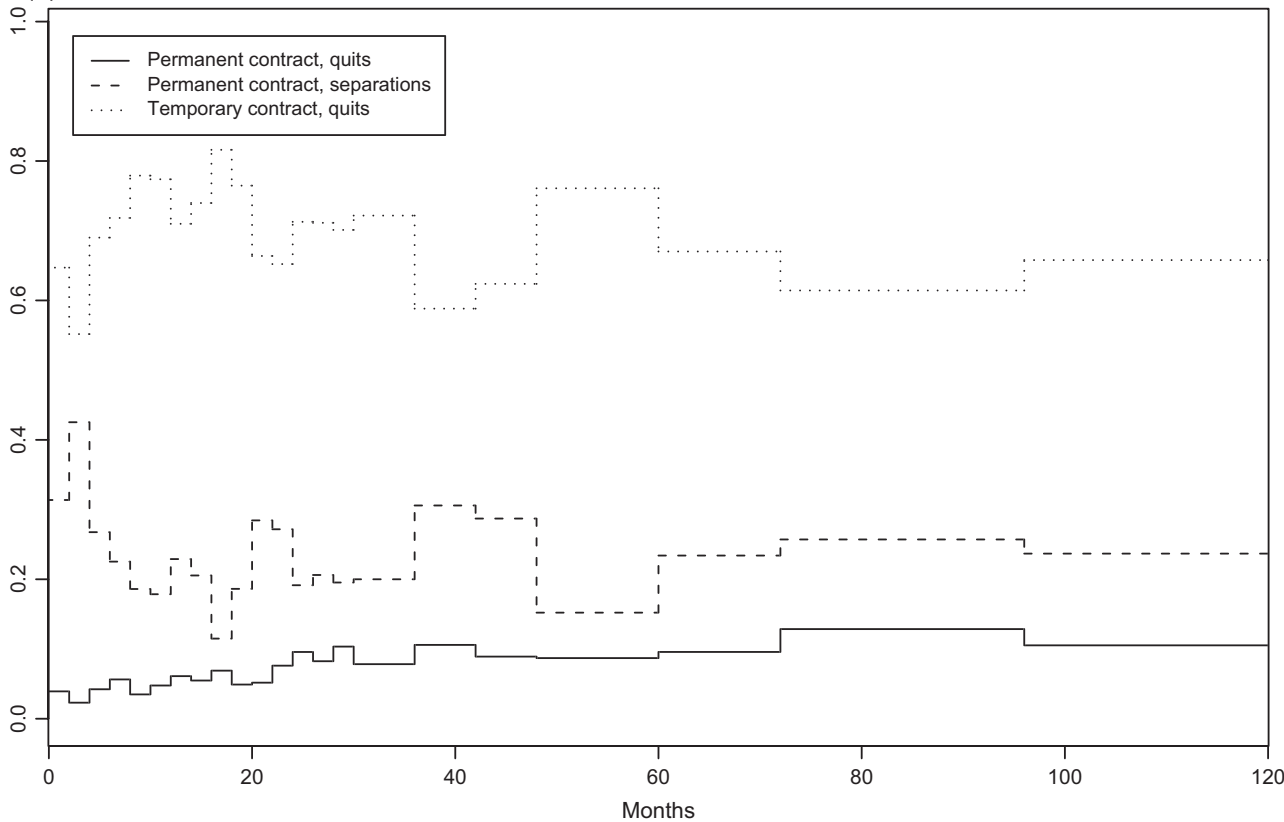

(C) 2012 The Economic Society of Australia 
TABLE 3

Estimated Marginal Effects for Competing Risk Models, Females (with Heterogeneity)

\begin{tabular}{|c|c|c|c|c|c|c|}
\hline & \multicolumn{2}{|c|}{ Combined quits } & \multicolumn{2}{|c|}{ Permanent quits } & \multicolumn{2}{|c|}{ Temporary quits } \\
\hline & $\begin{array}{c}\text { Marginal } \\
\text { effect }\end{array}$ & $P$-value & $\begin{array}{c}\text { Marginal } \\
\text { effect }\end{array}$ & $P$-value & $\begin{array}{c}\text { Marginal } \\
\text { effect }\end{array}$ & $P$-value \\
\hline Permanent & 0.657 & 0.000 & & & & \\
\hline ATSI & 0.294 & 0.000 & 0.171 & 0.000 & 0.090 & 0.000 \\
\hline NESB & -0.004 & 0.000 & -0.006 & 0.100 & -0.038 & 0.000 \\
\hline Disability & 0.224 & 0.000 & 0.300 & 0.000 & 0.090 & 0.000 \\
\hline Managers & -0.189 & 0.467 & -0.084 & 0.000 & 0.119 & 0.000 \\
\hline Nurses & 0.385 & 0.000 & 0.354 & 0.000 & 0.094 & 0.277 \\
\hline Teachers & -0.569 & 0.000 & 0.081 & 0.000 & -0.378 & 0.000 \\
\hline Other professional & -0.051 & 0.000 & -0.116 & 0.000 & 0.017 & 0.031 \\
\hline Associate professional & -0.266 & 0.336 & -0.485 & 0.862 & 0.034 & 0.188 \\
\hline Intermediate craft & -0.068 & 0.926 & -0.393 & 0.396 & 0.199 & 0.005 \\
\hline Advanced clerical & -0.230 & 0.024 & -0.404 & 0.877 & 0.004 & 0.008 \\
\hline Intermediate production & -0.313 & 0.116 & -0.326 & 0.014 & -0.099 & 0.774 \\
\hline Elementary clerical & -0.310 & 0.000 & -0.351 & 0.296 & -0.033 & 0.001 \\
\hline Estalishment size & 0.000 & 0.000 & 0.000 & 0.000 & 0.000 & 0.000 \\
\hline Establishment sick & 0.106 & 0.308 & 0.165 & 0.044 & -0.002 & 0.000 \\
\hline Relative wage & 0.184 & 0.000 & 1.178 & 0.000 & -0.027 & 0.513 \\
\hline Ln(unemployment) & -0.426 & 0.001 & -0.072 & 0.000 & -0.042 & 0.000 \\
\hline Individuals & \multicolumn{2}{|c|}{111,816} & \multicolumn{2}{|c|}{93,207} & \multicolumn{2}{|c|}{18,609} \\
\hline Observations & \multicolumn{2}{|c|}{$2,069,876$} & \multicolumn{2}{|c|}{$1,864,650$} & \multicolumn{2}{|c|}{205,226} \\
\hline Log (variance) & \multicolumn{2}{|c|}{8.958} & \multicolumn{2}{|c|}{9.829} & \multicolumn{2}{|c|}{7.180} \\
\hline Log likelihood & \multicolumn{2}{|c|}{$-32,043.1$} & \multicolumn{2}{|c|}{$-23,999.2$} & \multicolumn{2}{|c|}{-7362.4} \\
\hline
\end{tabular}

Notes: ATSI, Aboriginal or Torres Strait Islanders background; NESB, Non-English Speaking Background).

varying measure of the relative wage. We do observe the wage paid to workers in the public sector, and compute a measure of the relative wage by first estimating an occupation-age earnings profile for all workers using the Queensland 1996 Population Census. The coefficients from this model are then used to generate a predicted private sector weekly wage for all workers in the public sector. Deflating by the Queensland CPI series 5, we then derive the private/public sector weekly wage. Our results for the relative wage variable are broadly consistent with our findings on the unemployment shock variable. Workers on permanent contracts facing higher relative wages are more likely to quit. This relationship is not apparent for females on temporary contracts.

(ii) Are Nurses and Teachers More Likely to Quit?

Estimates on a number of covariates are included in Tables 3 and 4, however, for brevity, we eschew a discussion of many of them and focus on the occupational differences in quit and separation rates. It is clear that when we combine permanent and temporary workers, nurses are more likely to quit the profession and teachers less likely than labourers (the omitted case), and when compared to other professional workers in the public sector. For females, all other occupational groups are less likely to quit, so making the finding for nursing even more striking. For males, the story is slightly more complicated insofar as male nurses are not the only group to be more likely to quit; intermediate craft and other professional workers also exhibit this behaviour. Nevertheless, the probability of quitting nursing is much higher than for the other two groups.

Disaggregating by contract type also reveals a more complex story with respect to the mobility decisions of workers in different occupational groups. Table 3 shows that it is permanent female nurses who are more likely to quit rather than temporary workers, however, this group is still more likely to quit than suffer a termination. Female teachers on permanent contracts 
TABLE 4

Estimated Marginal Effects for Competing Risks Models, Males (with Heterogeneity)

\begin{tabular}{|c|c|c|c|c|c|c|}
\hline & \multicolumn{2}{|c|}{ Combined quits } & \multicolumn{2}{|c|}{ Permanent quits } & \multicolumn{2}{|c|}{ Temporary quits } \\
\hline & $\begin{array}{c}\text { Marginal } \\
\text { effect }\end{array}$ & $P$-value & $\begin{array}{c}\text { Marginal } \\
\text { effect }\end{array}$ & $P$-value & $\begin{array}{c}\text { Marginal } \\
\text { effect }\end{array}$ & $P$-value \\
\hline Permanent & 0.386 & 0.000 & & & & \\
\hline ATSI & 0.272 & 0.000 & 0.217 & 0.000 & 0.038 & 0.000 \\
\hline NESB & 0.054 & 0.263 & 0.045 & 0.749 & -0.012 & 0.025 \\
\hline Disability & 0.128 & 0.000 & 0.067 & 0.017 & 0.075 & 0.000 \\
\hline Managers & -0.015 & 0.001 & -0.042 & 0.197 & 0.003 & 0.143 \\
\hline Nurses & 0.659 & 0.000 & 0.206 & 0.000 & 0.061 & 0.615 \\
\hline Teachers & -0.295 & 0.000 & 0.361 & 0.019 & -0.221 & 0.000 \\
\hline Other professional & 0.116 & 0.033 & -0.010 & 0.000 & -0.008 & 0.001 \\
\hline Associate professional & -0.009 & 0.000 & -0.131 & 0.000 & -0.015 & 0.000 \\
\hline Intermediate craft & 0.159 & 0.021 & 0.315 & 0.001 & 0.007 & 0.054 \\
\hline Advanced clerical & -0.077 & 0.002 & -0.171 & 0.006 & -0.014 & 0.017 \\
\hline Intermediate production & -0.178 & 0.005 & -0.291 & 0.085 & -0.040 & 0.022 \\
\hline Elementary clerical & -0.151 & 0.588 & -0.201 & 0.794 & -0.020 & 0.429 \\
\hline Establishment size & 0.000 & 0.000 & 0.000 & 0.000 & 0.000 & 0.000 \\
\hline Establishment sick & 0.061 & 0.300 & 0.139 & 0.001 & -0.011 & 0.000 \\
\hline Relative wage & 0.202 & 0.000 & 0.541 & 0.000 & 0.000 & 0.004 \\
\hline Ln(unemployment) & -0.168 & 0.000 & -0.052 & 0.044 & 0.062 & 0.000 \\
\hline Individuals & \multicolumn{2}{|c|}{65,701} & \multicolumn{2}{|c|}{56,697} & \multicolumn{2}{|c|}{9004} \\
\hline Observations & \multicolumn{2}{|c|}{$1,287,613$} & \multicolumn{2}{|c|}{$1,192,140$} & \multicolumn{2}{|c|}{95,473} \\
\hline Log (variance) & \multicolumn{2}{|c|}{2.772} & \multicolumn{2}{|c|}{5.196} & \multicolumn{2}{|c|}{9.427} \\
\hline Log likelihood & \multicolumn{2}{|c|}{$-17,436.0$} & \multicolumn{2}{|c|}{$-13,008.5$} & \multicolumn{2}{|c|}{$-41,71.4$} \\
\hline
\end{tabular}

Notes: ATSI, Aboriginal or Torres Strait Islanders background; NESB, Non-English Speaking Background).

are also more likely to quit, which means that our previous finding for teachers was driven by contract status. In fact, female teachers on temporary contracts are much less likely to suffer a termination. A similar story arises for male nurses and teachers. Finally, comparing the genders, female nurses are more likely to quit than their male counterparts and, conversely, male teachers are more likely to quit than their female counterparts. Since both are female dominated occupations, the finding for the nursing profession appears particularly problematic.

Our observation of a higher probability of quitting amongst nurses on permanent contracts in particular is a cause for concern, and suggests that the retention problem is very real. In theoretical terms, this behaviour may reflect their low expected valuation of the quality of the match, which could be driven by a number of factors. First, nurses are in high demand in both the private and overseas sectors, and although wages are generally lower in the former, conditions of service are better, and so they may be lured out of the public sector. Second, in recent years nurses have suffered from serious morale problems, associated with gender discrimination with respect to promotion prospects, and would therefore be expected to have an increased probability of quitting (Pudney \& Shields, 2000; Shields \& Ward, 2001; Shields \& Wheatley Price, 2002). The first and second arguments could explain the high quit rates for males and females. A third argument which might explain the differential in quitting between male and female nurses is the argument put forward by Stinebrickner (2002), albeit with respect to US teachers, that female nurses leave to start a family. To investigate this hypothesis further, we calculated the proportion of exits disaggregated by age and gender. We found almost no difference in the proportion of exits between males and females for the 25-35 age group, the period in which child-bearing for females is most likely, implying that leaving nursing for childrearing cannot explain the gender differential in the turnover rate. 
TABLE 5

Occupational Differences in the Response to Relative Wages and External Shocks

\begin{tabular}{|c|c|c|c|c|c|c|}
\hline & \multicolumn{3}{|c|}{ Relative wages } & \multicolumn{3}{|c|}{ Unemployment } \\
\hline & $\begin{array}{c}\text { Marginal } \\
\text { effect }\end{array}$ & SE & $P$-value & $\begin{array}{c}\text { Marginal } \\
\text { effect }\end{array}$ & SE & $P$-value \\
\hline \multicolumn{7}{|l|}{ Terminations } \\
\hline Managers & -0.167 & 0.050 & 0.055 & 0.041 & 0.491 & 0.035 \\
\hline Nurses & -0.143 & 1.020 & 0.000 & 0.103 & 0.814 & 0.817 \\
\hline Teachers & -0.295 & 0.257 & 0.000 & 0.077 & 0.295 & 0.000 \\
\hline Other professionals & -0.024 & 0.237 & 0.000 & 0.038 & 0.257 & 0.028 \\
\hline Associate professionals & -1.449 & 0.343 & 0.000 & 0.065 & 0.259 & 0.812 \\
\hline Intermediate craft & na & & & na & & \\
\hline Advance/intermediate clerical & -0.084 & 0.090 & 0.385 & 0.382 & 0.340 & 0.000 \\
\hline Intermediate production & 0.206 & 1.167 & 0.030 & -0.117 & 0.906 & 0.163 \\
\hline Elementary clerical & 0.105 & 0.237 & 0.000 & 0.281 & 0.708 & 0.000 \\
\hline \multicolumn{7}{|l|}{ Quits } \\
\hline Managers & 0.167 & 0.092 & 0.000 & -0.041 & 0.332 & 0.010 \\
\hline Nurses & 0.143 & 0.286 & 0.000 & -0.103 & 0.203 & 0.023 \\
\hline Teachers & 0.295 & 0.779 & 0.000 & -0.077 & 0.257 & 0.771 \\
\hline Other professionals & 0.024 & 0.239 & 0.000 & -0.038 & 0.176 & 0.043 \\
\hline Associate professionals & 1.449 & 0.277 & 0.000 & -0.065 & 0.230 & 0.161 \\
\hline Intermediate craft & 0.078 & 0.285 & 0.000 & -0.071 & 0.329 & 0.000 \\
\hline Advanced/intermediate clerical & 0.084 & 0.124 & 0.000 & -0.382 & 0.195 & 0.101 \\
\hline Intermediate production & -0.206 & 1.667 & 0.337 & 0.117 & 0.974 & 0.065 \\
\hline Elementary clerical & -0.105 & 0.401 & 0.002 & -0.281 & 0.654 & 0.009 \\
\hline
\end{tabular}

Notes: Standard errors and $P$-values refer to the underlying coefficients.

The findings with respect to teachers are surprising since, according to the 1996 Australian Census, state school teachers in Queensland earned approximately $\$ 90$ per fortnight more than their private school counterparts and state school teachers have had significant pay increases since then. ${ }^{13}$ However, the private schools typically offer better working conditions, which could attract public sector teachers. There may also be the lure of work in other sectors of the economy. Nevertheless, what is clear from the results is that the pay increases for public sector teachers have not yet had the desired effect on retention since teachers on permanent contracts are more likely to quit. Furthermore, the fact that quits from teaching are more likely amongst males suggests that, in contrast to the findings for the USA, family reasons are unlikely to be the main contributor to quit decisions.

\footnotetext{
${ }^{13}$ For instance, Queensland teachers received a 14 per cent pay rise between 2000 and 2002, 5 per cent in 2000 and the remainder in 2001 and 2002.
}

The finding of different turnover patterns between nurses and teachers is perhaps surprising as they represent workforces which are in many ways similar and face similar human resource environments. They have both moved to graduate entry, are characterised by a large degree of government monopsony power, are heavily feminised and both have a significant reserve workforce. The differences documented in our results may reflect some unobserved variation in human resource practices across the two groups. However, we are unable to find evidence of this and the data do not allow us to explore this further.

\section{(iii) Occupational Differences in the Effect of Relative Wages and External Shocks}

We turn now to a discussion of whether occupational differences in mobility arise because of their different responses to relative wages and external shocks. To do this, we estimate separate models for each occupational group, which also allows the effect of the other control variables in the model to vary. The limitation of this approach is that for some occupational groups 
the number of exits is low, hence we are forced to combine males and females and temporary and permanent workers. ${ }^{14}$ However, we are still able to offer some tentative evidence on the effect of relative wages and external shocks on quits and terminations for each occupational group (see Table 5).

Higher relative wages have the expected effect, they increase the risk of quitting in most occupational groups, with particularly large effects in occupations that have skills that are more transferable to the private sector, that is, managers, teachers and associate professionals. Intermediate production and elementary clerical workers, who are relatively unskilled, are more likely to separate, an effect that is probably due to there being a larger proportion of workers in these occupational groups on temporary contracts. Indeed, the coefficient on the 'permanent' variable in the models underpinning the results for terminations in Table 5 is always large, negative and highly statistically significant, implying that temporary workers are used as a buffer to possible wage shocks that may increase the public sector wage bill.

A higher local unemployment rate reduces the risk of quitting, however, there are some noticeable differences in the responses of occupational groups. For instance, clerical workers (advanced through to elementary) are more likely to be shaken out when unemployment rises, whereas more highly skilled managerial and professional workers do face a higher risk of separation, but the effects are generally small. To see this, compare the marginal effect for managers of 0.04 with that of advanced/intermediate clerical workers of 0.38 , a differential of 34 percentage points. What this evidence suggests is that when unemployment rises, 'less skilled' workers in entry level jobs, who are also more likely to be on temporary contracts, are released, whereas 'highly skilled' workers are hoarded. This makes sense insofar as less skilled workers are in greater supply in the labour market and can always be recruited as and when they are required. Conversely, highly skilled workers have specific skills that are valuable to the

\footnotetext{
${ }^{14} \mathrm{~A}$ further issue is that there were convergence difficulties with respect to standard errors for the marginal effects from these models. As a result Table 5 reports the standard errors for the underlying coefficient and the $P$-values refer to these.
}

public sector and they are in relatively scarce supply in the labour market.

Whilst these results provide information on how outside factors influence occupational turnover decisions, due to their pooled nature across contract status they may obscure within occupation across contract variation. This seems potentially unsatisfactory given the differences in response by temporary and permanent workers highlighted in Tables 3 and 4. Ideally, we would re-estimate our models separately for temporary and permanent contract workers. However, due to small cell sizes, we are unable to gain precise estimates from our duration models at this level of disaggregation. Instead, we re-estimated the models reported in Table 5 with the addition of an interaction term between temporary contracts and both relative wages and unemployment.

These estimates suggest that the across contract variation in the response to outside factors reported earlier is driven by higher skilled occupations. For instance, there is no statistically significant difference in the response of temporary and permanent workers to outside conditions for those in craft, clerical, production or labouring occupations. There is also no contract-based variation for associate professionals. For the other groups, managers, teachers and other professional temporary workers' quit behaviour is less sensitive to relative wage movements. In all these cases, when the interaction term is combined with the main effect, this suggests that the quitting behaviour of temporary workers is unaffected by outside wages. This is in line with the estimates reported in Tables 3 and 4. The one outlier is nurses, for whom temporary workers' quitting behaviour is even more (positively) responsive to relative wages than permanent workers. In terms of quitting and the unemployment rate, contract differences are only evident for managers and associate professionals. In both of these cases, the sign of the interaction effect is negative, and the joint estimate is larger, negative (and statistically different from zero) when compared to those reported for the base model in Table 5. Hence, temporary workers in these two occupational groups have a larger negative relationship between the unemployment rate and quitting.

Looking at terminations, for other professionals and nurses there are differences in the response of temporary workers to relative wages. In both cases, the estimates of the interaction 
effect are positive and significant, and the joint effect is not statistically different from zero. Terminations for temporary workers in these two occupational groups are unresponsive to relative wages. Finally, in terms of the unemployment rate, temporary teachers' termination is less responsive but still positive and statistically significant.

\section{$V$ Conclusion}

The article asked a number of questions regarding the role of external shocks, relative wages and job status for turnover behaviour amongst public servants. In doing so, the study departed from past studies by analysing the behaviour of all public sector workers before examining the turnover of teachers and nurses. It made a number of important findings.

First, in relation to turnover decisions in the public sector as a whole, there is evidence that this labour market is affected by both external shocks (which runs counter to the conventional view that the public sector labour market is an insulated internal labour market) and relative wages. Specifically, we find, a higher local unemployment rate is associated with an increase in terminations, a counter-cyclical effect, and a decrease in voluntary quitting, a pro-cyclical effect. Our results for the relative wage variable are broadly consistent with our findings on the unemployment shock variable. Workers on permanent contracts facing higher relative wages are the most likely to quit within the public service, except for males on temporary contracts.

In contrast to Harris and Adams (2007), we find that nurses and teachers on permanent contracts are more likely to quit the public sector, compared to other occupational groups, but there are gender differences in the propensity to quit. The impact of job status also varies across occupations. Teachers on temporary contracts are more likely to separate, whereas nurses on temporary contracts are more likely to quit. Most other occupational groups of workers separate, and, in contrast to the existing literature, we show that those who do exit the public sector also have substantial work experience; a further correction to the standard internal labour market theory which argues that workers maximise rent on experience by staying within their organisation.

We do find evidence of non-monotonic hazards for males on permanent contracts and for temporary workers, even after allowance is made for unobserved heterogeneity. However, rather than observing a rising hazard, which then falls and becomes constant, in the public sector, we find evidence of spikes at 12 and 24 months, followed by a flat hazard. This reflects institutional arrangements in the Australian public sector. As predicted, temporary workers are more likely to exit the sector than permanent workers; however, terminations dominate quits, which is contrary to the predictions of the model.

The above results have some important implications for public policy regarding the labour force management of public servants, particularly nurses and teachers. The traditional view that higher skilled public servants were risk averse, traded conditions for wages and were isolated from external shocks is difficult to support from our findings. Specifically, we differ from the conclusions of Stinebrickner (2002) and find that permanent public servants, particularly teachers and nurses, are influenced by relative wages in their quitting decisions.

However, in some part, their behaviour may be influenced by the increasing propensity of governments to hire temporary workers and to terminate these workers in the face of external shocks. In other words, the stability of public sector employment, at least for some workers, from the demand side is now no longer as secure as it previously was and this may be inducing some supply side responses such as a loss of loyalty and a greater willingness to explore job offers from outside the public service.

If this is the case, public sector employers are faced with an interesting dilemma. The turnover decisions of public servants are influenced by a complex mix of wages and conditions, however, our results suggest that to increase the retention of skilled workers such as nurses and teachers, employers will need to pay more attention to relative wages. Conversely, they may seek to re-examine the strategic use of buffer stock (temporary) labour to restore some of the attributes of the traditional internal labour market which played down relative wages and emphasised stability of employment.

\section{REFERENCES}

Ahlburg, D. and Mahoney, C. (1996), 'The Effect of Wages on the Retention of Nurses', Canadian Journal of Economics, 29, 126-9. 
Andrews, M., Bradley, S. and Stott, D. (2002), 'Matching the Demand For and Supply of Training in the School-to-Work Transition', Economic Journal, 112, C201-19.

Australian Bureau of Statistics (1997), Trade Union Statistics Australia. Catalogue 6325.0 Belconnen, ACT.

Belfield, R. and Marsden, D. (2006) 'Pay for Performance Where Output is Hard to Measure: The Case of Performance Pay for School Teachers', CEPDiscussion Paper No. 747, Centre for Economic Performance, London School of Economics and Political Science, London.

Bishop, J.H. (1990), 'Job Performance, Turnover and Wage Growth', Journal of Labor Economics, 8, 363-86.

Borjas, G. (2003), 'Wage Structures and the Sorting of Workers Into the Public Sector', in Donahue J. and Nye J. (eds), For The People: Can We Fix Public Service? Brookings Institution Press, Washington; 81.

Borland, J. and Gregory, R.G. (1999), 'Recent Developments in Public Sector Labor Markets', in Ashenfelter O. and Card D. (eds), The Handbook of Labor Economics, Vol. III. Elsevier, Amsterdam, 3573-630.

Bradley, S., Crouchley, R. and Oskrochi, R. (2003), 'Social Exclusion and Labour Market Transitions: A Multi-State Multi-Spell Analysis Using the BHPS', Labour Economics, 10, 659-79.

Cabinet Office (1999), Modernising Government. HMSO, London.

Chevalier, A., Dolton, P. and McIntosh, S. (2007), 'Recruiting and Retaining Teachers in the UK: An Analysis of Graduate Occupation Choice From the 1960s to the 1990s', Economica, 74, 69-96.

Contini, B. and Ravelli, R. (1997), 'Gross Flows Versus Net Flows in the Labour Market: What is There to be Learned?' Labour Economics, 4, 245-63.

Dolton, P. and van der Klaauw, W. (1995), 'Leaving Teaching in the UK: A Duration Analysis', Economic Journal, 105, 431-44.

Dolton, P. and van der Klaauw, W. (1999), 'The Turnover of Teachers: A Competing Risks Explanation', The Review of Economics and Statistics, 81, 543-50.

Farber, H.S. (1994), 'The Analysis of Interfirm Worker Mobility', Journal of Labor Economics, 12, 554-93.

Flinn, C.J. (1986), 'Wages and Job Mobility of Young Workers', Journal of Political Economy, 94, S88-110.

Frijters, M., Shields, M. and Wheatley Price, S. (2004), 'To Teach or Not to Teach: Panel Data Evidence on the Quitting Decision', IZA Discussion Paper No. 1164, Bonn.

Green, C. and Leeves, G. (2004), 'Casual Jobs and Internal Labour Markets', Manchester School, 72, $658-76$.

Harris, D. and Adams, S. (2007), 'Understanding the Level and Causes of Teacher Turnover: A Comparison With Other Professions', Economics of Education Review, 26, 325-37.
Heckman, J. and Singer, B. (1984), 'Econometric Duration Analysis', Journal of Econometrics, 24, 63132.

Imazeki, J. (2005), 'Teacher Salaries and Teacher Attrition', Economics of Education Review, 76, 193-205.

Jovanovic, B. (1979), 'Job Matching and the Theory of Turnover', Journal of Political Economy, 8, 972-90.

Jovanovic, B. and Moffitt, R. (1990), 'An Estimate of a Sectoral Model of Labor Mobility', Journal of Political Economy, 98, 827-52.

Kim, M. (1999), 'Where the Grass is Greener: Voluntary Turnover and Wage Premiums', Industrial Relations, 38, 584-603.

Lancaster, T. (1990), The Econometric Analysis of Transition Data. Cambridge University Press, Cambridge.

Mangan, J. (2000), Workers Without Traditional Employment: An International Study of NonStandard Work. Edward Elgar, Cheltenham.

McLaughlin, K. (1991), 'A Theory of Quits and Layoffs With Efficient Turnover', Journal of Political Economy, 99, 1-29.

Meitzen, M.E. (1986), 'Differences in Male and Female Job-Quitting Behavior', Journal of Labor Economics, 4, 151-67.

Mont, D. and Rees, D. (1996), 'The Influence of Classroom Characteristics on High School Teacher Turnover', Economic Inquiry, 34, 152-67.

Nickell, S. and Quintini, G. (2002), 'The Consequences of the Decline in Public Sector Pay in Britain: A Little Bit of Evidence', The Economic Journal, 112, 107-18.

OECD (1997) Trends in Public Sector Pay. OECD (PUMA), Paris.

OECD (1999) The Structure of Civil Service Employment in Seven OECD Countries. OECD (PUMA), Paris.

Prentice, R. and Gloeckler, L. (1978), 'Regression Analysis of Grouped Survival Data With Application to Breast Cancer Data', Biometrics, 34, 57-67.

Pudney, S. and Shields, M. (2000), 'Gender and Racial Discrimination in Pay and Promotion for NHS Nurses', Oxford Bulletin of Economics and Statistics, 62, 801-35. Special Issue

Shields, M. and Ward, M. (2001), 'Improving Nurse Retention in the National Health Service in England: The Impact of Job Satisfaction on Intentions to Quit', Journal of Health Economics, 20, 677-701.

Shields, M. and Wheatley Price, S. (2002), 'Racial Harassment, Job Satisfaction and Intentions to Quit: Evidence From the British Nursing Profession', Economica, 69, 295-326.

Stinebrickner, T. (2002), 'An Analysis of Occupational Change and Departure From the Labour Force: Evidence of the Reasons That Teachers Leave', Journal of Human Resources, 37, 192-216.

Thomas, J. (1996), 'On the Interpretation of Covariate Estimates in Independent Competing-Risks Models', Bulletin of Economic Research, 48, 27-39. 